\title{
Big science and human development - what is the connection?
}

\section{AUTHORS: \\ Michael Gastrow ${ }^{1}$}

Thelma Oppelt ${ }^{1}$

\section{AFFILIATION:}

${ }^{1}$ Human Sciences Research

Council - Education and Skills

Development, Cape Town,

South Africa

\section{CORRESPONDENCE TO: \\ Michael Gastrow}

EMAIL:

mgastrow@hsrc.ac.za

\section{DATES:}

Received: 03 Nov. 2017

Revised: 30 May 2018

Accepted: 12 July 2018

Published: 27 Nov. 2018

\section{KEYWORDS:}

economic development; innovation; science engagement;

SKA telescope; large-scale science facilities

\section{HOW TO CITE:}

Gastrow M, Oppelt T. Big science and human development what is the connection? S Afr J Sci. 2018;114(11/12), Art. \#5182, 7 pages. https://doi. org/10.17159/sajs.2018/5182

\section{ARTICLE INCLUDES: \\ $\times$ Supplementary material \\ $\times$ Data set}

\section{FUNDING:}

DST-NRF Centre of Excellence in Human Development (South Africa) (c) 2018. The Author(s). Published under a Creative Commons Attribution Licence.
The rationale for public expenditure and political support for large-scale science infrastructure is commonly underpinned by a universalist logic of big science's benefits. Literature assessing the impact of big science focuses on its contributions towards new fundamental insights about the universe; the development of skills, capabilities, networks, and innovation; and the development of globally transformative technology platforms that in turn make significant impacts on global human development. However, research into the local development impact of big science infrastructure is scarce. In this paper we reflect on the development impact of a big science project at the local level, drawing on the case study of the Square Kilometre Array telescope in South Africa's Karoo region. We find that the universalist logic that appears to apply at the global and national levels does not necessarily apply at the local level, where big science has resulted in human development benefits, but also substantial economic and social costs. On this basis we recommend that big science infrastructures, particularly in marginalised areas of developing countries, require a localised development proposition that takes into account local social complexities on the basis of extensive local engagement.

\section{Significance:}

- A synthetic review is presented of the different causal pathways through which big science may impact on human development.

- Analytical distinctions are developed between the human development impacts of big science at the global, national, and local scales.

- Considerations are put forward for a developmental agenda for big science facilities, particularly in developing countries.

\section{Introduction}

The presence of the Square Kilometre Array telescope (SKA) on the African continent has prompted reflection about the juxtaposition between large-scale globalised science and its host environment in South Africa's arid, sparsely populated and geographically isolated Karoo region. In a country where poverty, inequality and unemployment are serious social challenges, the human development implications of all policy choices, including science policy choices, are critical. To contribute to the national conversation about science policy and human development, including that related to the SKA, we present key findings from a literature review examining the relation between big science and human development. The literature review forms part of a project undertaken for the DST-NRF Centre of Excellence in Human Development. We apply general principles of this relation to the SKA, with the aims of gaining new insights into the manner in which this large-scale research infrastructure contributes to human development and reflecting on the big science-human development relation from a South African point of view.

The notion of 'big science' has emerged as shorthand for the increasingly large science projects that first proliferated during the Cold War. ${ }^{1-3}$ The term was coined in $1961^{4}$ to refer to a post-war political economy in which scientific research was a national security priority requiring state intervention and resources, as manifested for example in the first particle accelerators, as well as the Manhattan Project and much of the work of DARPA. The term 'largescale science facilities' is also commonly used to refer to big science ${ }^{5}$, primarily in relation to a facility's scale and role in systems of innovation. Nonetheless, in debates about human development impact, the two terms are broadly interchangeable. ' 'Large-scale research infrastructure' has been seen to include telescopes; accelerators; facilities for biomedical research; sources for laser, neutron or synchrotron radiation, molecular imaging techniques, high magnetic fields, etc.; and high-performance supercomputers and grids. ${ }^{5}$

The rise of big science meant that scientists had to work in increasingly large hierarchical teams, and manage demands from new stakeholders: government, subcontractors and supply chains. Other analytical dimensions that distinguish big science from the broader scientific landscape include issues of geography (the growth of big science to encompass, sometimes literally, cities or regions), economics (the proliferation of multibillion dollar projects), multidisciplinarity (big science requires multiple academic disciplines and engineering technologies), and globalisation (big science projects generally require international collaboration at many levels). ${ }^{2}$

The knowledge and technology developed within big science facilities not only advance our understanding of the universe, but generate new classes of products and services that disrupt markets and change lives. At the same time, big science requires big funding, and hence policy trade-offs and public approval..,7 The scale of big science projects means that they exist in the public sphere - the notional space in which open debate takes place about matters of public interest. ${ }^{8}$ In this public sphere, big science projects require social legitimacy, underpinned by public acceptance and mutual benefit. Such a social contract should ideally be supported by human development outcomes that justify the financial and opportunity costs of big science projects. Cultural, social and political contexts play important roles in shaping public perceptions of science. ${ }^{9}$ For example, understanding public acceptance has been a key factor in informing the strategic decisions of nuclear fusion facilities, as it is for 
the human genome project. ${ }^{10-12}$ In both cases, public perceptions of the risks and benefits associated with big science play a central role in framing science projects as publicly acceptable or not. So, what is the relationship between big science and human development?

We began our analysis by examining some of the leading contemporary conceptions of human development, with a focus on Amaryta Sen's notion of 'development as freedom'13, and Manual Castells' analysis of human development in the 'information age' ${ }^{14}$, which position human development in relation to technological change, skills and knowledge, through a systemic actor-network analysis. On the basis of this conception of development, and its links to science and innovation, we examined the evidence and analysis of the relationship between big science and human development, and we put forward an abstracted model of the main causal pathways between them.

To explore the relationship between big science and human development in South Africa, our empirical focus shifts to South Africa's flagship science project, the SKA. We examined the (potential) human development implications of the SKA at the global, national and local levels. We explored the manner in which the human development implications of the SKA align with generalised conceptions of the big science-human development relationship, and the manner in which contextual factors determine a unique relationship at the local level. Through doing so, we aimed to extend the analysis of the role of big science in human development to include greater reflection about local impact, particularly for marginalised communities and developing countries.

\section{Science, technology and human development}

The theoretical debate over the nature of development is broad, and contains many strands which address different purposes and concepts. ${ }^{15}$ In contrast to the study of economic development, which is focused on the dynamics of economic activity, the study of human development has a broader focus on the question of human well-being. This scope approximately aligns with the United Nations Sustainable Development Goals, and their aim of increasing prosperity and harmony in a sustainable world.

A suitable starting point for conceptualising human development is the consensus emerging from the 'intellectual coup' initiated by $\operatorname{Sen}^{16}$, which re-framed the notion of human development as a question of access and capabilities, rather than economic resources. Sen ${ }^{16}$ thus placed people at the centre of the development discourse. This conception of human development focuses on the cultivation of agency and capability, access to opportunity, and the freedom to work towards self-realisation in accordance with one's own beliefs and values. Development thus requires increasing levels of freedom, whether negative freedoms (freedoms from hunger, disease, poverty) or positive freedoms (freedom of self-expression, freedom of self-realisation). $\operatorname{Sen}^{17}$ argues that freedom and capability are inextricably linked: freedom without the capability of its own realisation cannot contribute towards development. For example, famines may occur, not from lack of food, but because of a lack of resources to buy food. The freedom to achieve food security is meaningless without the capability to achieve it in practice. Sen's focus on capabilities and the development of human agency suggests that human development as an outcome of science and technology interventions should ideally be achieved through processes that include capability-building, social engagement and public participation.

For Castells, human development, also conceived as the freedom to exercise human capabilities, is tied to the production of resources and modes of social organisation that are increasingly dominated by technological drivers. ${ }^{18,19}$ Castells conceives of these broad socioeconomic dynamics as a shift into the 'global information age'. This age is defined as 'a historical period characterised by the technological revolution in information and communication, the rise of networking forms of social organisation, and the global interdependence of economies and societies'20. Castells views the organisation of infrastructures and activities for the creation, processing and transmission of information to be the main driver of wealth creation, a process termed 'informational development'. ${ }^{19,20}$ The notion of informational development suggests that assessments of the relation between science, technology and human development include a focus on access to the Internet, to information and communication technology (ICT) more broadly, and to opportunities for technological upgrading, and their impacts on human development.

Castells' conception of the relationship between science and technology on the one hand, and human development on the other, is aligned with an innovation systems theory of wealth generation, in which value is created by 'transforming information into knowledge, and then applying knowledge to all the tasks to be executed on the basis of the technological and human capability embedded in the system'20. Innovation is commonly defined as the development of new products, processes or organisational structures. ${ }^{21}$ Some strands of the innovation literature consider technology diffusion into households and the informal sector. ${ }^{22}$ Innovation has a broad scope: a new product or process can be entirely novel, 'new to the world', or it can be 'new to the country', 'new to the sector', or 'new to the firm'. ${ }^{21,23,24}$ The most common scale of analysis is at the national level, hence the term 'national systems of innovation' (NSI), defined as 'the network of institutions in the public and private sectors whose activities and interactions initiate, import, modify and diffuse new technologies'22. The NSI approach ${ }^{25,26}$ remains widely used in the innovation studies literature ${ }^{27}$, and has become the standard theoretical framework for guiding national and international science and technology policy ${ }^{27,28}$.

Skills are fundamental enablers of innovation activity. ${ }^{28}$ Without the requisite skills, new basic science cannot be performed, and new technologies cannot be developed, adapted or disseminated. The innovation studies literature suggests a strong causal interaction between the supply of higher levels of education, training and skills and increased demand for and supply of technical and organisational innovation. ${ }^{29,30}$ Innovation and skills development are thus intertwined in an unfolding process that has been described as 'co-evolution'. ${ }^{11,32}$ Co-evolution mechanisms include firm-level learning, technology and skills transfers through multinational corporations, local spillovers from innovation activities within firms, firmlevel responses to the availability of local skills in terms of innovation activity, and university-firm interactions. ${ }^{33,34}$

Innovation systems analysis is largely concerned with understanding informational development as an input towards human development, rather than about human development per se. However, some strands of research within the discipline take the assessment of this relationship a step further. In his analysis of the linkages between techno-economic development and human development, Castells observed that despite the advancement of technologies, in particular ICTs, the majority of the global population remain in economically fragile and technologically excluded positions. ${ }^{35}$ This concern also drove increased interest in 'innovation in inclusive development'. ${ }^{21,27}$ This intersection between innovation systems analysis and development studies raises questions about the manner in which big science projects have, or have not, been inclusive and helped to drive social development. Key areas of investigation are the inclusiveness of the innovation process, the nature of participation among marginalised communities, and innovation in low-income and informal settings. ${ }^{36}$

\section{Big science and human development}

Given the significance of big science as a driver of technological change and knowledge generation, and the importance of human development as normative and policy goal, previous reviews of the intersection of these two domains have found a 'surprising lack of evidence on the nature and extent of the impacts of large-scale research facilities on the economy and society and on the mechanisms that generate such effects ${ }^{\prime 37}$. Moreover, there is a lack of consensus in the literature over the reliability and generalisability of evidence about big science and innovation. The extant evidence does not encompass the full range of big science, as 'the evidence is skewed and cannot be extrapolated to the entire architectural and disciplinary diversity' of big science. ${ }^{37}$ Although many researchers have made extensive claims about the effects of big science on innovation and economic growth, one review found 'insufficient evidence to support the claim that [big science 
facilities] attract and retain talent and promote innovation', although 'more evidence exists that large infrastructures forge new networks and communities' ${ }^{\prime 37}$. However, the authors identified a lack of evidence, rather than a lack of impact - pointing towards the need for more research in this area in order to build an empirical base and move towards conceptual consensus.

These limitations notwithstanding, the logic underpinning analyses of the human development impact of big science is essentially 'universalist', supported by claims that the advances made by big science underpin most contemporary technological advancements, and through this advancement make an almost incalculable contribution to human development globally. ${ }^{37}$ The rationale for public support for big science appeals to this universalist logic - according to which even the large financial costs incurred by basic science are outweighed by the (often unforeseen) benefits to humanity. At the same time, however, critiques of big science facilities have long questioned their return on investment, their proximity to military and industrial powers, and their opportunity cost in relation to scientific enterprises that have more direct benefits for human well-being. ${ }^{4}$ The overall assessment of the contribution of big science to human development extends far beyond the scope of this paper. It may indeed be impossible to develop any meaningful quantitative assessment of the human development contribution of big science. However, the literature does establish a number of 'development logics' - notional processes through which big science facilitates or constrains human development - and these form the basis for our conceptualisation of a generic model of this relationship.

Figure 1 illustrates this model, showing the main causal pathways between big science and human development. We distinguish between the global and local scales, which are characterised by their inverse degrees of abstraction and specificity. The human development logic of big science is at its most abstract in the analysis of its global impact, whereas analyses of local human development impacts are largely determined by the specific social and economic context.

Firstly, as a backdrop to all human development considerations, the benefits of big science facilities need to be weighed against their financial costs, and the associated opportunity costs of dedicating resources to big science rather than more direct human-development-oriented interventions: 'Opportunity costs are at the heart of [the] issue' ${ }^{37}$. Trade-offs are made more difficult by the fact that the social benefits of scientific research are uncertain and take long to materialise..$^{38}$
The logic of financial and policy trade-offs requires a clear conception of the benefits that will accrue with science expenditure. Such benefits are diverse, and of manifestly different types. Firstly, new knowledge contributes towards human development. New fundamental knowledge about reality has a normative value (understanding reality is a good in and of itself) and a positive value, as a more complete comprehension of the workings of the universe is a priori likely to have practical benefits too. Weighing up the nature of such benefits is difficult, as the normative value of new knowledge may vary across cultures, and the developmental impact of new fundamental knowledge is unpredictable and widely distributed across many economic and social formations.

Evidence and analysis are therefore largely focused on more material benefits. Some science facilities have an explicit social mission for example biobanks or national reference laboratories, which are established to benefit public health, supported by scientific research. For such facilities, the social benefits are demonstrable, as they are tied to mission outcomes. However, most big science facilities exist for scientific purposes only, for example radio telescopes or particle accelerators: 'the challenge is to identify the societal footprint of facilities with a primary scientific mission'37.

For such science facilities, innovation appears to be the primary mechanism through which human development outcomes are realised. Institutional assessments of big science projects, for example of CERN $^{39}$ and the European Extremely Large Telescope ${ }^{40}$, and reviews by multilateral organisations such as the $\mathrm{OECD}{ }^{41}$, use an innovation systems framework, reflecting a primary interest in innovation, learning and economic impact, and focusing on technological and economic development as an output of interactions between actors in the system, and between systemic functions. Such institutional assessments have identified the main impacts of big science to be its influence on adjacent fields of science and technology, innovation incentives for industrial suppliers through procurement activity, and impact through community engagement and technology transfer. ${ }^{42} \mathrm{~A}$ review undertaken by the OECD found that big science projects boost innovation and push knowledgeintensive work to world-class quality. ${ }^{41}$ More specific applications of innovation theory include studies of how big science centres operate as learning environments for industrial supplier firms ${ }^{42}$, as well as the broader mutual benefit of joint innovation processes between industry and big science ${ }^{43}$. A relatively extensive literature argues that social capital is the most significant factor in spillovers from big science into the private sector. ${ }^{40,43}$

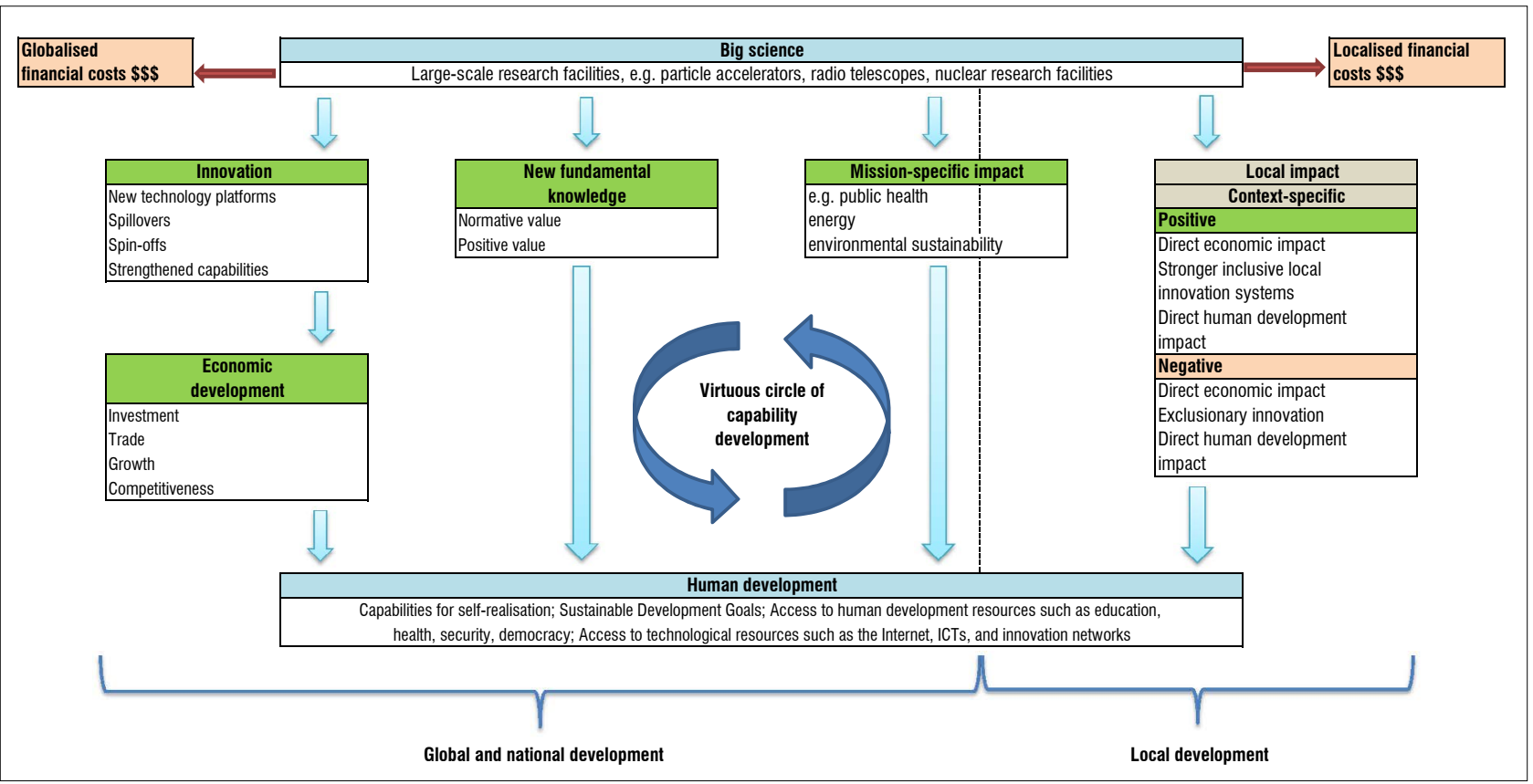

Figure 1: Big science and human development relationship in abstract. 
Overall, taking into account the empirical limitations, our review identified a generalised pattern to the innovation benefits of big science: large research infrastructures attract the world's best researchers, on the basis of which the facility becomes a cluster or hub of knowledge in which there is heightened interaction between the scientific and the technological functions of the facility. ${ }^{37}$ The interactions between big science centres, universities, industry and research institutes can be described as a virtuous circle, in which capabilities are strengthened through interaction, mutual learning and network building. As a consequence, there is consensus in the literature that big science provides a positive return on investment, and is of substantial net benefit to society ${ }^{37,44}$, even taking into account the large financial and opportunity costs.

The technologies developed for big science facilities are diffused into other sectors of society, creating economic benefits for innovators and social benefits for society. ${ }^{45}$ Related to these benefits is the potential of commercial spin-offs based on new technologies and capabilities developed for science projects. ${ }^{46}$ Research-based spin-offs are small, new technology-based firms whose intellectual capital originated in universities or other public research organisations. Innovation spillovers occur when an organisation stimulates external technological improvements through internal innovation. Such external benefits often outweigh the initial investment in big science, although such benefits are not immediate. ${ }^{47}$ The benefits of spin-offs are partly conjectural at the beginning of a big science project, but may emerge as their main contribution to society by maturity of the project.

Big science facilities, along their path of pursuing new fundamental knowledge, have pushed the boundaries of technology, and through this enabled the establishment of technological platforms such as the Internet, Wi-Fi, the transistor, nuclear energy, GPS, touch screens, genetic medicine, and so on. Such advances have historically been generally serendipitous, for example, the development of the touch screen and the World Wide Web at CERN ${ }^{41}$, and the origins of the Internet within the USA's National Physics Laboratory and associated supercomputer systems ${ }^{48}$. The net contribution of such technological platforms to human progress is indeed incalculable, and can perhaps best be understood as diffuse global drivers of technological change, and all the attendant impacts on development.

Studies that focus on the social and cultural effects of big science are far less numerous than those using an innovation lens. Previous reviews have pointed out a general paucity of studies looking at the social impact of big science. ${ }^{5}$ Extant research is often indirect and more diverse in its theoretical perspectives; for example, the sociology of knowledge creation in big-science contexts ${ }^{49}$, using social constructivism theory to examine impacts of large-scale research facilities ${ }^{50}$, and using grounded theory together with theoretical constructs from social network, social capital, and inter-organisational learning theories ${ }^{42}$. A broad overview of the social impacts of big science, in which seven case studies of largescale science facilities were explored, showed that 'the least understood, yet potentially the most significant aspect of big science facilities operates through their broader contributions to society and culture'5.

Whereas global and national scales allow for an abstraction of the relationship between big science and human development, at the local scale the relationship is more context specific, may include both significant positive and negative impacts, and may fall outside the techno-economic scope that forms the focus of assessments at national and global levels. The few studies that focus on local impact are located in developed countries, and also focus on the innovation and economic mediating processes, rather than human development as an ends. For example, a study of the impact of the Fermilab on the city of Chicago and the State of Illinois ${ }^{51}$ found that direct expenditure boosted the local economy by USD288 million, and created 4500 jobs which led to net earnings to households and businesses in the region of USD643 million. The human development impact, for example as related to the Sustainable Development Goals, was not assessed. However, further research into the human development impact of the new employment and income would conceivably reveal significant benefits.
Not all big science projects experience harmonious relationships with their host publics. To use an example in the astronomy domain, the Thirty Metre Telescope in Hawaii, while under construction and on course to become a flagship international instrument, had its construction permit revoked on the grounds that public consultation processes had not been followed. ${ }^{52,53}$ Mauna Kea is the most sacred mountain in Hawaiian culture, and one of the key objections was that the instrument would be built on a sacred ancestral burial ground. In this case, negative local impacts led to a breakdown in legitimacy that presented a material risk to the project. Importantly, the local developmental cost was unrelated to scientific, innovation or economic outcomes. Instead the objection related to local participation, agency and culture - issues that are aligned with Castells' notion of agency and participation being central to the relationship between science, technology and human development.

\section{The Square Kilometre Array and human development}

The SKA, currently under construction, will become the world's largest telescope. In South Africa and its eight African partner countries, the high- and mid-frequency radio receiver array will include approximately 2000 15-metre-wide receiver dishes, all linked via fibre-optic cable and supercomputers. In Australia, the low frequency array will consist of tens of thousands of small antennae dipoles. The SKA's primary science questions are related to the origins of the universe, the formation of the first stars and galaxies, the nature of dark matter and dark energy, theories of gravity and relativity, and the search for extra-terrestrial life.

The project has a global set of stakeholders, funders and employees, and a globalised innovation network. ${ }^{54}$ The SKA has distinct implications for the two main host countries, South Africa and Australia, African partner host countries (Botswana, Ghana, Kenya, Madagascar, Mauritius, Mozambique, Namibia and Zambia), the headquarter country (the UK), and the eight other countries in the global SKA consortium (Canada, China, India, Italy, New Zealand, Sweden, the Netherlands and the UK). Conceptualisation of the SKA's relation to human development therefore needs to span the global and the local, the immediate and the long term. Within the South African context, the Karoo region - including the towns of Carnarvon, Williston, Loxton and Brandvlei, as well as surrounding farming communities - forms an important localised setting for assessing the impact of the SKA. The impact in urban centres such as Cape Town and Gauteng is also significant because of the location of the SKA's central and regional offices. The impact on universities, other astronomy facilities, and South Africa's broader high-skills economy, are all potential areas for investigation.

The SKA provides a promising case study for assessing the big sciencehuman development relationship, and in particular may add to the literature addressing this question in Africa and in developing countries. To guide this assessment, we examined the SKA in terms of its adherence to the postulated generic model of big science and human development, and examined the local context to explore how this relationship has been manifested in South Africa's Karoo region. Within this framework, key analytical questions that emerged from our conceptualisation of human development and innovation included those related to access to ICT, opportunities for technological upgrading, the inclusiveness of the innovation process, the nature of participation among marginalised communities, and evidence of movement towards human development goals such as increased health, literacy and employment.

The core knowledge and financial parameters of the SKA at the global level align with the generalised model of big science and human development. The cost of the international project ${ }^{55}$ is estimated at EUR1.8 billion, representing a significant opportunity cost, and a requirement for funders to provide substantiation to their stakeholders and constituencies. The expenditure will be distributed globally across the two infrastructure sites in Australia and South Africa, in South Africa's eight African partner countries, the headquarters in the United Kingdom, and throughout the SKA's global supply chain and innovation network. ${ }^{54}$ The South African government is contributing significantly to the financing of the telescope: 
ZAR2.3 billion has been set aside for the 2018 Medium Term Expenditure Framework, which covers a 3-year period. ${ }^{56}$

The generation of new fundamental knowledge by the SKA, like other big science projects, has the potential to revolutionise our conception of the universe and our place therein. Progress in even one of its six main science objectives would enormously advance our understanding of physics and cosmology. Technological breakthroughs could also have enormous global benefits. It is conceivable that advances in the areas of big data, supercomputing, and algorithm development may generate new technological platforms with a global impact and widespread implications for human development. However, it is difficult, if not impossible, to foresee what such implications might be.

At the national level, the impact of the SKA on technological capabilities and the NSI may prove to be its greatest, albeit indirect, contribution to human development in South Africa. A NSI with enhanced capabilities can compete more effectively in the global knowledge economy, and play a greater role in economic growth and development. Building knowledge transfer capabilities by enhancing coordination, interaction and alignment between skills supply and skills demand is an important contribution of the SKA to the NSI. These contributions include mechanisms such as the Universities Working Group, which informally coordinates skills development activities at South African universities; participation in the National Astrophysics and Space Sciences Programme Steering Committee, which coordinates postgraduate curricula at the universities; and SARChl Chairs in various science and engineering focus areas relevant to the SKA, which bring in international expertise as well as local expertise, and draw on this expertise to develop new knowledge and skills among postgraduate students and postdoctoral positions. ${ }^{54}$

Technology diffusion and technological spin-off activity is another manner in which the SKA strengthens the NSI and contributes towards economic growth. Technological capabilities built within the SKA find their way into other sectors, particularly those that utilise big data, advanced ICTs, and engineering - although the nature of such spillovers has not been subject to research. In terms of spin-off activity, the SKA has a dedicated office to support this function, which is seen as important to its public benefit role in the NSI and to strengthening its own financial sustainability. Privatesector spin-off firms cultivate new economic activity by participating in high-tech global value chains ${ }^{54}$ However, the nature and extent of these effects have not been comprehensively researched, pointing the way towards a future research agenda in this area.

Given the significance of the co-evolution of skills and innovation capabilities, a central aspect of the SKA's contribution in South Africa has been its Human Capital Development Programme (HCDP), which aims to develop the capabilities of engineers, scientists, technicians and artisans to build, operate and use the SKA. At the inception of the HCDP in 2005, South Africa was home to only a handful of radio astronomers, and had limited technical capabilities - while competing against an internationally competitive and much larger Australian radio astronomy sector. Today, the sector has grown by orders of magnitude: as of 2017, the HCDP had awarded 943 grants to support postdoctoral fellows, postgraduate and undergraduate students, and students training to be artisans, and had also funded five dedicated university-based Research Chairs. The HCDP is funded by the Department of Science and Technology, and from 2005 to 2017 had cost a total of ZAR446 million. (Data provided by the SKA.)

Overall, therefore, the evidence suggests that, at the national level, the generalised model of the human development benefits of big science largely applies to the SKA too. However, at the local level, contextual factors become more significant, and the balance between benefits and costs is shifted. The areas surrounding the SKA's core site in the Karoo are where the project has its greatest direct exposure to local communities. The SKA has rendered substantial economic benefits to local communities. As of 2016, the organisation's activities in the Northern Cape Province have included ZAR136 million spent through local suppliers, and the creation of 7284 employment opportunities. ${ }^{57}$ In addition, indirect economic benefits include a growing market for accommodation and tourism. ${ }^{58}$ The local hospitality industry has benefitted, as visitors to the SKA must largely stay off-site, and find accommodation in surrounding towns - although these effects have yet to be measured.

In addition to the SKA's economic impact, the HCDP intersects with local communities through its schools programme. As of 2016, SKA had provided training to 351 people from Northern Cape communities, rolled out a support programme for eight local schools, involving more than 4000 learners, and funded 9 local students to attend university and 72 students to attend vocational colleges. Carnarvon High School has benefitted from a new computer lab, high-bandwidth Internet connection, bursaries, and direct engagements with the SKA. The SKA has also routed some resources towards direct human development interventions, on the basis of engagement with local community stakeholders. For example, the SKA has sponsored the Carnarvon Library, and is providing small-scale funding to a non-profit organisation that undertakes skills training, foetal alcohol syndrome awareness and intervention programmes, arts and crafts at the local high school, and a reading programme at the primary school.

However, there are also a range of economic costs to local communities that have resulted from the SKA. The purchase of farming land to host the telescope has removed the associated economic activity from local supply chains, negatively impacting on both upstream and downstream sectors. Examples include reduced demand for agricultural supplies bought from local firms, and reduced demand for services of the Carnarvon abattoir. The Strategic Environmental Assessment of the Council for Scientific and Industrial Research ${ }^{59}$ developed an economic model that predicted a loss in annual agricultural production of ZAR16 million, a loss in throughput at abattoirs equivalent to $8.24 \%$ of annual slaughter volumes, a drop in sales and business volumes amongst local business and entrepreneurs equivalent to ZAR9.09 million, and a loss in production value on neighbouring farms adjacent to the SKA core because of increased predator activity. Cumulatively, these effects would lead to an estimated economic loss of ZAR31 million annually, and a cumulative loss of 1565 jobs.

While the SKA has clearly contributed to South Africa's NSI, there is currently little evidence to suggest that local innovation systems in the Karoo have been strengthened. This question is a subject of current research being conducted by the Human Sciences Research Council for the National Research Foundation. The SKA core site, for technical reasons, remains closed to the public, and the advanced technologies deployed at the site have little or no impact in surrounding communities. Attempts to directly link to local systems of innovation may in any case be ineffective, given the large gap between the SKA's advanced technologies and local capacities to absorb new technologies. Moreover, the radio telescope has significantly constrained Internet access around its core site in the Karoo, negatively impacting on ICT access for some farmers and surrounding communities.

Castells' agent-centric notion of human development argues that social engagement and public participation should be central to science that seeks to contribute towards human development. This argument raises the question of the extent and efficacy of the SKA's engagement with local communities. The evidence here is mixed, revealing a wide range of engagement activities, as well as ongoing local dissatisfaction with engagement mechanisms. Local civic resistance to the SKA has catalysed around claims of insufficiently mitigated economic losses to special interest groups, and claims of inadequate local agency in the telescope's activities in the Karoo ${ }^{60}$ An open forum for community engagement was in 2016 shut down as a result of local opposition to the SKA ${ }^{61}$, and the SKA's primary local engagement platform has since then been through local municipalities. The socio-political dynamics of the interactions between civil society formations and the SKA is an area of ongoing research, including assessments of social media as a platform for resistance. ${ }^{62}$

At the local level, therefore, the relationship between big science (manifested in the SKA) and human development does not adhere to the same developmental logic that applies to the global level. There are immediate economic benefits and economic costs, and the causal path from big science to human development is more direct, rather than 
being mediated through complex innovation and economic systems. The new fundamental knowledge that may emerge from the telescope is of little current value to the local population, and local innovation systems have been minimally affected by the telescope. Instead, the main human development outcomes have been related to dedicated development initiatives, such as education interventions and social development interventions. The effects on the most pressing human development needs - poverty, unemployment, alcoholism, foetal alcohol syndrome, and other social problems - appears to be small, although it has yet to be measured; no impact assessments of the SKA's education and social interventions have yet been published.

\section{Reflections on big science and the developmental context}

The scale of big science opens up questions of scale for social scientists too: we need to define and disentangle the effects that big science has on the world, on nations, and on regions surrounding science infrastructure. It would be an error to see the effects at these different scales as being directly comparable - they differ enormously in terms of their economic scale and scope, time frames, predictability, measurability, causal mechanisms and policy context. The potential effects on humanity of new fundamental insights into the nature of reality, or the emergence of a new disruptive technological platform, cannot be meaningfully compared, in any direct sense, to the immediate impact of social development interventions surrounding a scientific facility. Nonetheless, the rationale for undertaking big science, and funding big science, must in some way take all these diverse effects into account, and proceed on the basis of a clear conceptualisation of human development impact that provides a balanced development proposition at all levels.

At the global and national levels, a broadly conceived consensus appears to exist (empirical limitations notwithstanding) with respect to the development logic underpinning claims about big science's contribution to global and national human development, firstly by placing value on the development of new fundamental knowledge in and of itself, and secondly through innovation as a mediating process that translates big science activities into economic and social benefits. However, this logic is less clearly defined at the local scale, where the economic and social benefits and costs are not mediated through complex global innovation and production systems, but rather result as a direct effect of a facility's social mission, or through employment, infrastructure, supply chains, local innovation systems and direct development interventions. At the local level, participation and agency become critical factors in terms of achieving a developmental process that aligns with conceptions of agency-based human development, as well as establishing social legitimacy and a 'licence to operate'.

In the case of the SKA, arguments for the extensive global and national benefits of the project are not relevant to local stakeholders, who are affected by immediate and local consequences. Extant evidence suggests that the local economic impact has, on balance, been positive, although special interest groups, such as the agricultural sector, may experience negative consequences. Capabilities have certainly been built, particularly through the SKA's schools programme. However, many of the innovation benefits of the SKA, including knowledge spillovers, economic spinoffs and capability development, occur in urban centres but not in the Karoo, showing that the postulated strengthening of innovation systems through big science may exclude marginalised groups and by-pass local systems of innovation. Local resistance in some instances frames local communities as lacking agency with respect to decisions about SKA, and as paying the true cost for the instrument.

These disjunctures suggest several imperatives for big science infrastructures, particularly those being built in developing countries and marginalised regions. Firstly, there is a need to balance global, national and local human development processes, priorities and outcomes. There is a need to put forward a development proposition that provides clear human development benefits at all levels. There is a need to include local stakeholders in decision-making processes. And there is a need to present a clear argument that global and national benefits, as enormous as they may be, are not being prioritised over local costs.

\section{Acknowledgements}

The support of the DST-NRF Centre of Excellence in Human Development is hereby acknowledged. Opinions expressed and conclusions arrived at, are those of the authors and are not necessarily to be attributed to the Centre of Excellence in Human Development. We thank Prof. Linda Richter and Dr Vijay Reddy for their valuable contributions at various stages of the research. We also thank all the SKA staff and members of the Carnarvon and Loxton communities who participated in the research.

\section{Authors' contributions}

M.G.: conceptualisation, project leadership, project management, funding acquisition, methodology, analysis, writing initial draft, writing revisions. T.0.: conceptualisation, data collection, literature review.

\section{References}

1. Kaiser D. From blackboards to bombs: Seventy years after the destruction of Hiroshima and Nagasaki by nuclear weapons, David Kaiser investigates the legacy of 'the physicists' war'. Nature. 2015;523(7562):523-526. https:// doi.org/10.1038/523523a

2. Galison P, Hevly B, Weinberg AM. Big science: The growth of large-scale research. Phys Today. 1992;45:89. https://doi.org/10.1063/1.2809880

3. Sullivan WT, editor. The early years of radio astronomy: Reflections fifty years after Jansky's discovery. Cambridge: Cambridge University Press; 2005.

4. Weinberg AM. Impact of large-scale science on the United States. Science. 1961;134(3473):161-164. https://doi.org/10.1126/science.134.3473.161

5. Autio $\mathrm{E}$. Innovation from big science: Enhancing big science impact agenda [document on the Internet]. c2014 [cited 2018 May 30]. Available from: http://data.parliament.uk/DepositedPapers/Files/DEP2014-0843/Innovationfrom-big-science-enhancing-big-science-impact-agenda.pdf

6. National Audit Office. Big science: Public investment in large scientific facilities. Norwich: The Stationery Office; 2007. Available from: https://www. nao.org.uk/report/big-science-public-investment-in-large-scientific-facilities

7. Cost.eu. Benefits of research infrastructures beyond science - The example of the Square Kilometre Array (SKA); 2010 March 30-31; Rome, Italy. Available from: http://www.cost.eu/events/ska

8. Habermas J. The structural transformation of the public sphere: An inquiry into a category of bourgeois society. Cambridge, MA: MIT Press; 1991.

9. Reddy V, Gastrow M, Juan A, Roberts B. Public attitudes to science in South Africa. S Afr J Sci. 2013;109(1-2), Art. \#1200, 8 pages. http://dx.doi. org/10.1590/sajs.2013/1200

10. Bauer MW. Public perceptions and mass media in the biotechnology controversy. Int J Public Opin Res. 2005;17(1):5-22. https://doi.org/10.1093/ ijpor/edh054

11. Prades López A, Horlick-Jones T, Oltra C, Solá R. Lay perceptions of nuclear fusion: Multiple modes of understanding. Sci Public Pol. 2008;35(2):95-105. https://doi.org/10.3152/030234208X282853

12. Cunningham-Burley $S$, Kerr A. Defining the 'social': Towards an understanding of scientific and medical discourses on the social aspects of the new human genetics. Sociol Health IIIn. 1999;21(5):647-668. https://doi. org/10.1111/1467-9566.00177

13. Sen A. Development as freedom. Oxford: Oxford University Press; 1999. http://dx.doi.org/10.2307/40203469

14. Castells $M$, Himanen $P$, editors. Reconceptualizing development in the global information age. Oxford: Oxford University Press; 2014. https://doi. org/10.1093/acprof:0so/9780198716082.001.0001

15. Pieterse JN. Development theory. London: Sage; 2009. http://dx.doi. org/10.4135/9781446279083

16. Sen AK. Equality of what? In: McMurrin S, editor. Tanner lectures on human values. Cambridge: Cambridge University Press; 1995. p. 197-220. https:// doi.org/10.1093/0198289286.003.0002

17. Sen AK. Development as capability expansion. In: DeFilippis J, Saeger S, editors. The community development reader. 2nd ed. New York: Routledge; 2012. p. 319-327. https://doi.org/10.1007/978-1-349-21136-4_3 
18. Castells M. Materials for an exploratory theory of the network society. $\mathrm{Br} \mathrm{J}$ Sociol. 2000;51(1):5-24. https://doi.org/10.1080/000713100358408

19. Castells M, Himanen P. The information society and the welfare state: The Finnish model. Oxford: Oxford University Press; 2002.

20. Castells MH. Reconceptualizing development in the Global Information Age: Oxford: Oxford University Press; 2014

21. Martin BR. The evolution of science policy and innovation studies. Res Policy. 2012;41(7):1219-1239. https://doi.org/10.1016/j.respol.2012.03.012

22. Freeman C. The 'National System of Innovation' in historical perspective. Cambridge J Econ. 1995;19(1):5-24.

23. Nelson R, Winter S. An evolutionary theory of economic change. Cambridge, MA: Belknap Press; 1982.

24. Mowery D, Rosenberg N. Technology and the pursuit of economic growth. Cambridge: Cambridge University Press; 1991.

25. Lundvall BÅ. National systems of innovation: Towards a theory of innovation and interactive learning. London: Pinter; 1992.

26. Nelson RR, editor. National innovation systems: A comparative analysis. Oxford: Oxford University Press; 1993

27. Lundvall BÅ. Innovation system research and policy. Where it came from and where it might go. Paper presented at: InCAS Seminar; 2007 December 04; Oslo, Norway.

28. Fagerberg J, Verspagen B. Innovation studies - The emerging structure of a new scientific field. Res Policy. 2009;38(2):218-233. https://doi.org/10.1016/j. respol.2008.12.006

29. Toner P. Workforce skills and innovation: An overview of major themes in the literature. OECD Education Working Papers. 2011;(55):0_1.

30. Cohen WM, Levinthal DA. Absorptive capacity: A new perspective on learning and innovation. Adm Sci Q. 1990;35(1)128-152. https://doi.org/10.2307/2393553

31. Lewin AY, Couto V. Next generation offshoring: The globalization of innovation: 2006 survey report. Durham, NC: Centers for International Business Education and Research (CIBER), Duke University; 2007.

32. Losby B. Knowledge, institutions and evolution in economics. London: Routledge; 2000.

33. Metcalfe JS. Evolutionary economics and creative destruction. London: Routledge; 1998. https://doi.org/10.4324/9780203275146

34. Lorentzen J. MNCs in the periphery: DaimlerChrysler South Africa (DCSA), human capital upgrading and regional economic development. In: Multinationals on the periphery. London: Palgrave Macmillan; 2007. p. 158-187. https://doi. org/10.1057/9780230593046_7

35. Castells M. End of millennium. Vol. III: The information age: Economy, society and culture. Oxford: Oxford University Press; 1998.

36. Cozzens S, Sutz J. Innovation in informal settings: A research agenda. Ottawa, Canada: International Development Research Centre; 2012.

37. Horlings E, Gurney T, Somers A, Van den Besselaar P, Van Saksenlaan A. The societal footprint of big science. Rathenau Instituut working paper. Den Haag: Rathenau Instituut; 2012. Available from: http://hdl.handle. net/20.500.11755/16c47732-84e4-4a9a-8c2f-be53d12eade4

38. Martin BR, Tang P. The benefits from publicly funded research. Brighton: Science Policy Research Unit, University of Sussex; 2007.

39. Autio E, Hameri AP, Bianchi-Streit M. Technology transfer and technological learning through CERN's procurement activity. Geneva: CERN; 2003.

40. Science and Technology Facilities Council (STFC). E-ELT impact: The impact of the European Extremely Large Telescope. Edinburgh: STFC; 2009. Available from: www.eelt.org.uk/astronomers/elt-impact.pdf

41. Organisation for Economic Development and Co-Operation (OECD). The impacts of large research infrastructure on economic innovation and on society: Case studies. Paris: OECD; 2014. Available from: http://www.oecd. org/sti/sci-tech/CERN-case-studies.pdf

42. Autio E. Innovation from big science: Enhancing big science impact agenda London: Department of Business, Innovation \& Skills, Imperial College Business School; 2014.
43. Autio E, Hameri AP, Vuola O. A framework of industrial knowledge spillovers in big-science centres. Res Policy. 2004;33(1):107-126. https://doi. org/10.1016/S0048-7333(03)00105-7

44. Vuola 0, Hameri AP. Mutually benefiting joint innovation process between industry and big-science. Technovation. 2006;26(1):3-12. https://doi. org/10.1016/j.technovation.2005.03.003

45. Hickling Arthurs Law Corporation. Return on investment in large scale research infrastructure. Ottawa: National Research Council; 2013.

46. Gómez AL. Technological spillovers of research infrastructures. Departmenta Working Papers 2015-18, Department of Economics, Management and Quantitative Methods at the University of Milano. 2015. Available from: http:// wp.demm.unimi.it/files/wp/2015/DEMM-2015_18wp.pdf

47. Byckling $E$, Hameri AP, Pettersson T, Wenninger $H$. Spin-offs from CERN and the case of TuoviWDM. Technovation. 2000;20(2):71-80. https://doi. org/10.1016/S0166-4972(99)00113-3

48. Rizzuto $\mathrm{C}$. Benefits of research infrastructures beyond science. Presented at: ERFWorkshop on the Socio-Economic Relevance of Research Infrastructures 2012 May 31 - June 01; Hamburg, Germany.

49. Yates DM. Turing's legacy: A history of computing at the National Physical Laboratory 1945-1995. London: Science Museum; 1997. p. 126-146.

50. Knorr CK. Epistemic cultures. How the sciences make knowledge. Cambridge, MA: Harvard University Press; 1999.

51. Sallee CM, Watkins SD, Rosaen AL. The economic impact of Fermi National Accelerator Laboratory. Anderson Economic Group report to the University of Chicago [document on the Internet]. c2011 [cited 2018 May 30]. Available from: https://ovprnl.uchicago.edu/sites/research.uchicago.edu/files/Fermilab_ Economic_I mpact_Full_Study.pdf

52. Sanders GH. The thirty meter telescope (tmt): An international observatory. J Astrophys Astron. 2013;34(2):81-86. https://doi.org/10.1007/s12036-0139169-5

53. Overbye D. Hawaii court rescinds permit to build thirty meter telescope. New York Times. 2015 December 03. Available from: https://www.nytimes. com/2015/12/04/science/space/hawaii-court-rescinds-permit-to-buildthirty-meter-telescope.html? $r=0$

54. Gastrow M. Understanding interactive capabilities for skills development in sectoral systems of innovation: A case study of astronomy and the Square Kilometre Array telescope. LMIP report 6. South Africa: Labour Market Intelligence Partnership; 2015. Available from: http://www.Imip.org.za/sites/ default/files/documentfiles/HSRC\%20LMIP\%20Report\%206\%20Web_0.pdf

55. Frequently asked questions about the SKA [webpage on the Internet]. No date [cited 2018 May 30]. Available from: https://www.skatelescope.org/ frequently-asked-questions/

56. National Treasury. Estimates of national expenditure 2018. Pretoria: National Treasury; 2018. Available from: http://www.treasury.gov.za/documents/ national\%20budget/2018/enebooklets/Vote\%2030\%20Science\%20and\%20 Technology.pdf

57. Adam R. SKA SA's investment impact on the Northern Cape. SKA Resources. 2017. Available from: http://www.ska.ac.za/wp-content/uploads/2017/03/ ska_investment_northern_cape_2017.pdf

58. Ingle M. Making the most of 'nothing': Astro-tourism, the sublime, and the Karoo as a 'space destination'. Transform Crit Perspect South Afr. 2010;74(1):87111. https://doi.org/10.1353/trn.2010.0013

59. Council for Scientific and Industrial Research (CSIR). Strategic environmental assessment for the South African mid-frequency array of SKA Phase 1. CSIR report CSIR/02100/EMS/ER/2016/15240/B. Pretoria: CSIR; 2016

60. Butler SS. Knowledge relativity: Carnarvon residents' and SKA personnel's conceptions of the SKA's scientific and development endeavors. Stellenbosch: Stellenbosch University; 2018.

61. Wild S. Giant SKA telescope rattles South African community. Nature. 2016;534:444-446. https://doi.org/10.1038/534444a

62. Binneman A. The SKA's struggles with anti-SKA advocacy groups. Presented at: Public Communication of Science and Technology Conference; 2018 April 03-06; Dunedin, New Zealand. 